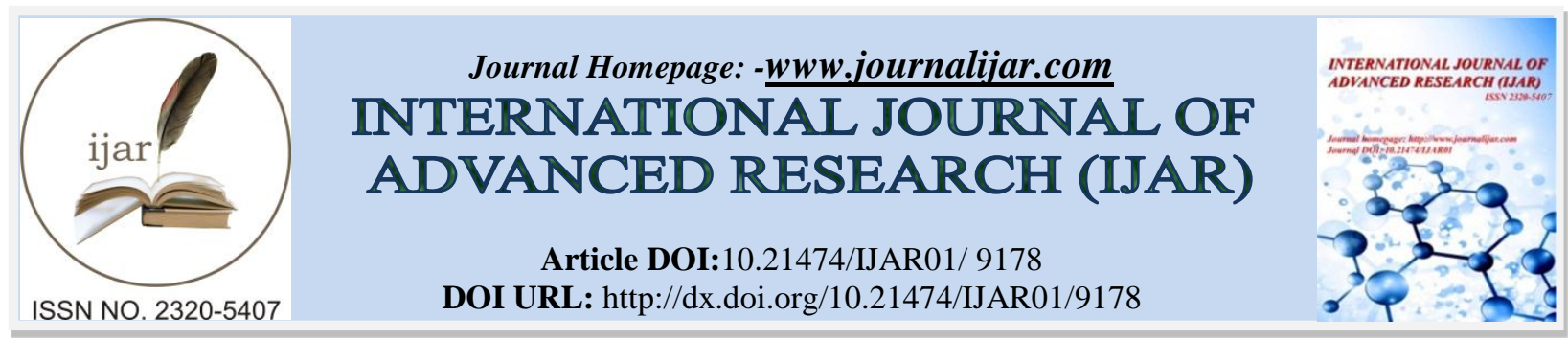

RESEARCH ARTICLE

\title{
RISK STRATIFICATION AND 90 DAYS OUTCOME OF IMPAIRMENT OF KIDNEY FUNCTION IN PATIENTS WITH CIRRHOSIS BY CAUSES AND REVISED CONSENSUS BY INTERNATIONAL CLUB OF ASCITES.
}

\footnotetext{
Dr.Rishabh Prakash Jain ${ }^{1}$, Dr.Parul Jain ${ }^{2}$, Dr.Vineet Chaudari ${ }^{3}$, Dr.Ravichandra $\mathrm{NS}^{3}$ and Dr.Ajit kumar ${ }^{4}$.

1. Lecturer in Gastroenterology Department,Deenanath Mangeshkar Hospital ,Pune 411004 (Ex senior resident Nizam's Institute of health sciences,Hyderabad 500082.

2. Junior resident MGM Medical College Navi Mumbai.

3. Senior resident Department of Gastroenterology Nizam's Institute of health sciences,Hyderabad.

4. Ex Head of department Department of Gastroenterology Nizam's Institute of health sciences,Hyderabad .
}

\section{Manuscript Info}

Manuscript History

Received: 26 March 2019

Final Accepted: 28 April 2019

Published: May 2019

Key words:-

Cirrhosis,renal dysfunction,Hepatorenal syndrome, causes of renal failure.

\section{Abstract}

Introduction: Cirrhotic patients with acute renal failure have poor survival. We aimed to examine the association between type of acute kidney injury, cause and 90-day survival.

Methods: This was a prospective observational study in a tertiary centre of consecutive patients admitted with cirrhosis and renal dysfunction in a tertiary centre. They were classified according to revised consensus and by the cause of renal failure: renal failure associated with infections; hypovolemia; hepatorenal syndrome (HRS) and parenchymal nephropathy. The primary end point was survival at 90 days.

Results: Total 112 patients had acute kidney injury during the study period from $1^{\text {st }}$ January 2016 to $31^{\text {st }}$ December 2016 . Renal dysfunction associated with infection (49.1\%) was most common cause followed by hypovolemia (28.7\%), HRS (18.7\%) and parenchymal renal diseases (3.5\%). Progression of renal dysfunction was seen in HRS group $(14 / 21,53.8 \%)$, followed by infection (20\%), hypovolemia (6\%) and parenchymal renal disease $(0 \%)$. Complete response to treatment was seen in hypovolemia group $(18 / 29,62 \%)$ followed by infection $(25 / 50$, $50 \%)$, parenchymal disease $(2 / 4,50 \%)$ and HRS $(0 \%)$ in decreasing order. HRS was associated with high mortality at 90 days $(20 / 21,95 \%)$, followed by infection (56\%), hypovolemia (41\%) and parenchymal renal diseases (25\%). Progression of renal dysfunction is independently associated with mortality.

Conclusion: The results of the current study confirm that acute kidney injury, as defined by International Club of Ascites, is associated with high 90 days mortality. Similarly classification by cause of renal dysfunction can predict mortality and outcome.

Copy Right, IJAR, 2019,. All rights reserved.
Corresponding Author:- Dr.Rishabh Prakash Jain.

Address:-Lecturer in Gastroenterology Department,Deenanath Mangeshkar Hospital ,Pune 411004

(Ex senior resident Nizam's Institute of health sciences,Hyderabad 500082. 


\section{Introduction:-}

Acute kidney injury (AKI) is a common complication in patients with decompensated cirrhosis. The International Club of Ascites (ICA) organised a consensus development meeting in Venice, Italy, in order to reach a new definition of AKI in patients with cirrhosis and recommendations consensus statement of the ICA introduced a new dynamic definition of AKI in patients with cirrhosis, on which a new treatment algorithm was based, representing a substantial change from the traditional criteria and definition of AKI and type 1 HRS ${ }^{(1)}$. Similarly classification of AKI according to cause of renal dysfunction has been used as prognostic factor in predicting mortality in cirrhosis by various studies ${ }^{(2,3)}$. Thus, the current study was designed to compare prospectively the AKI classification and causes in the prognostic stratification of hospitalised patients with cirrhosis and AKI.

\section{Methods:-}

This was a prospective observational study of consecutive patients admitted with cirrhosis in ward and ICU at a tertiary centre during January 2016 to December 2016. After obtaining informed consent consecutive patients more than 18 years of age with liver cirrhosis of any aetiology requiring admission seen at emergency medical department (EMD), out patients department (OPD) and those being admitted as in-patients at NIMS hospital Hyderabad which is tertiary care hospital were recruited. We excluded patients with prior kidney or liver transplant, advanced chronic kidney disease (baseline creatinine $>4.0 \mathrm{mg} / \mathrm{dL}$ ) prior to liver disease, obstructive uropathy, malignancy, HIV infection.The diagnosis of cirrhosis was based on clinical, radiological and laboratory parameters. History, physical examination, blood tests, and imaging studies were done. On admission each patient was evaluated for presence of renal dysfunction according to revised consensus recommendations of the International Club of Ascites (ICA)

${ }^{(1)}$.They were classified according to factors responsible for renal dysfunction into hypovolemia, infection, renal parenchymal changes and hepatorenal syndrome (HRS) by following definitions.

Renal failure associated with infections: Renal failure was considered secondary to an infection when patients had an ongoing infection in the absence of other causes of renal failure, using defined by standard diagnostic criteria.

Hypovolemia related renal failure: Renal failure was considered related to hypovolemia when patients had a history of fluid losses because of bleeding, diuretics, large volume paracentesis or other causes.

Parenchymal renal disease:-Renal failure because of parenchymal nephropathy was considered when there was either proteinuria greater than $500 \mathrm{mg} / 24$ hours, abnormal urine sediment with more than 50 red cells per high power field, or abnormal renal ultrasound findings in the absence of other causes of renal failure.

Hepatorenal syndrome (HRS):Hepatorenal syndrome was considered as per definition given by revised consensus recommendations of the International Club of Ascites ${ }^{(1)}$.

Definition of $\mathrm{AKI}^{(1)}$ : Increase in serum creatinine $(\mathrm{sCr}) \geq 0.3 \mathrm{mg} / \mathrm{dL}$ within $48 \mathrm{~h}$; or a percentage increase $\mathrm{sCr} \geq 50 \%$ from baseline which is known, or presumed, to have occurred within the prior 7 days.

\section{Baseline creatinine:}

A value of creatinine in the previous 3 months, when available, used as baseline creatinine.

Stages of AKI :Stage 1: Increase in $\mathrm{sCr} \geq 0.3 \mathrm{mg} / \mathrm{dL}$. Stage 2: Increase in $\mathrm{sCr}>$ two to threefold from baseline Stage 3: Increase of $\mathrm{sCr}>$ threefold from baseline or $\mathrm{sCr} \geq 4.0 \mathrm{mg} / \mathrm{dL}$ or initiation of renal replacement therapy.

Definition of progression of AKI :Progression: Progression of AKI to a higher stage and/or need for Renal Replacement Therapy .Stabilization: Maintenance of same AKI stage. Regression: Regression of AKI to a lower stage.

Definition of response to treatment : No response: No regression of AKI stage. Partial response: Regression of AKI stage with a reduction of $\mathrm{sCr}$ to $\geq 0.3 \mathrm{mg} / \mathrm{dL}$, above the baseline value. Complete response: Return of $\mathrm{sCr}$ to a value within $0.3 \mathrm{mg} / \mathrm{dL}$ of the baseline value.

Management of patient was according to standard guidelines as per institutional protocol. A review of patients with renal dysfunction was done on day 30 and day 90 from admission by calling the patient for follow up at OPD or by telephonic enquiry of patient is well being for those who could not come in person. 


\section{Statistical analysis:-}

Database management and the statistical analysis were performed using the SPSS (statistical package for social performance) v 16 software. Pearson's chi-square test was applied to test the relationship of categorized independent and dependent variables. A p value of $<0.05$ was deemed statistically significant. Risk factors were assessed by univariate analysis. Survival analysis was done by Kaplan Meier survival curve.

\section{Results:-}

Out of total 356 patients admitted with cirrhosis of liver 112 had renal dysfunction. Thus the total prevalence of renal dysfunction was $31.46 \%$. Out of total 112 patients with renal dysfunction 8 patients lost to follow up, 104 patients followed till 90 days, 61 (58.6\%) patients died and 43 (42.4\%) survived and were included in analysis. The base line characteristics both groups are given in table 1. In the present study it was observed that the mean age of patients in the study was $48.8 \pm 11.31$ yrs (range 21-72).

Table 1:-Baseline characteristics of patients with renal dysfunction with survival at 90 days

\begin{tabular}{|l|l|l|l|l|}
\hline & Total n=104 & $\begin{array}{l}\text { Survivor at 90 days } \\
\mathrm{n}=43(42.4 \%)\end{array}$ & $\begin{array}{l}\text { Non survivor at 90 days } \\
\mathrm{n}=61(58.6 \%)\end{array}$ & $\begin{array}{l}\mathrm{P} \\
\text { value }\end{array}$ \\
\hline Age in years & $48.88 \pm 11.31$ & $50.01 \pm 10.38$ & $48.38 \pm 11.34$ & 0.234 \\
\hline Male $\mathrm{n}(\%)$ & $93(89.4 \%)$ & $35(81.4 \%)$ & $58(95.1 \%)$ & 0.025 \\
\hline Cirrhosis etiology $\mathrm{n}(\%)$ & & & & \\
\hline Hepatitis B n(\%) & $8(7.7 \%)$ & $4(9.3 \%)$ & $4(6.6 \%)$ & 0.605 \\
\hline Hepatitis C n(\%) & $6(5.8 \%)$ & $4(9.3 \%)$ & $2(3.35)$ & 0.194 \\
\hline Alcohol n(\%) & $81(77.9 \%)$ & $27(62.8 \%)$ & $54(88.5 \%)$ & 0.002 \\
\hline $\begin{array}{l}\text { Non alcoholic steatohepatitis } \\
\text { (\%) }\end{array}$ & $6(5.8 \%)$ & $5(11.6 \%)$ & $1(1.6 \%)$ & 0.051 \\
\hline Others n(\%) & $5(4.8 \%)$ & $3(7 \%)$ & $2(3.3 \%)$ & 0.385 \\
\hline Reasons for admission n(\%) & & & & \\
\hline Refractory ascites & $89(85.6 \%)$ & $34(79.1 \%)$ & $55(90.2 \%)$ & 0.113 \\
\hline Oliguria & $44(42.3 \%)$ & $12(27.9 \%)$ & $32(52.5 \%)$ & 0.013 \\
\hline Gastrointestinal bleed & $26(25 \%)$ & $11(25.6 \%)$ & $15(24.6 \%)$ & 0.908 \\
\hline Jaundice & $73(70.2 \%)$ & $19(44.2 \%)$ & $54(88.5 \%)$ & $<.0001$ \\
\hline Others & $33(31.7 \%)$ & $12(27.9 \%)$ & $21(34.4) \%$ & 0.482 \\
\hline Encephalopathy & $53(50.96 \%)$ & 16 & 37 & 0.0191 \\
\hline Total Infection n(\%) & $77(74.3 \%)$ & 29 & 48 & 0.197 \\
\hline $\begin{array}{l}\text { Spontaneous } \\
\text { peritonitis }\end{array}$ & $15(14.4 \%)$ & $6(14 \%)$ & $9(14.8 \%)$ & 0.909 \\
\hline Urinary tract infections & $31(29.8 \%)$ & $14(32.6 \%)$ & $17(27.9 \%)$ & 0.607 \\
\hline $\begin{array}{l}\text { Lower respiratory } \\
\text { infections }\end{array}$ & $16(15.4 \%)$ & $3(7.0 \%)$ & $13(21.3 \%)$ & 0.046 \\
\hline Skin infections & $6(5.8 \%)$ & $3(7 \%)$ & $3(4.9 \%)$ & 0.657 \\
\hline Others & $9(8.7 \%)$ & $3(7 \%)$ & $6(9.8 \%)$ & 0.610 \\
\hline $\begin{array}{l}\text { MELD score } \\
\text { (mean } \pm \text { SD) }\end{array}$ & $21.44 \pm 5.59$ & $19.44 \pm 5.55$ & $29.39 \pm 5.68$ & $<0.001$ \\
\hline $\begin{array}{l}\text { CTP score } \\
\text { (mean } \pm \text { SD) }\end{array}$ & $9.82 \pm 1.55$ & $9.46 \pm 1.51$ & $11.04 \pm 1.14$ & $<0.001$ \\
\hline Child B n(\%) & $23(22.1 \%)$ & $19(44.2 \%)$ & $4(6.6 \%)$ & $<0.001$ \\
\hline Child C n(\%) & $81(77.9 \%)$ & $24(55.8 \%)$ & $57(93.4 \%)$ & \\
\hline
\end{tabular}

Refactory ascites and jaundice were the most common symptoms at presentation. Symptoms of ascites, jaundice, oliguria and encephalopthy were significantly associated with mortality $(\mathrm{p}<0.05)$. Urinary tract infections $(29.4 \%$ )were most common infections. Lower respiratory tract infection was associated with reduced survival( $p$ $<0.05)$.Similarly CTP and MELD score were significantly associated with survival at 90 days $(\mathrm{p}<0.05)$. 
Table 2:-Risk Stratification according to cause of renal failure and survival at 90 days

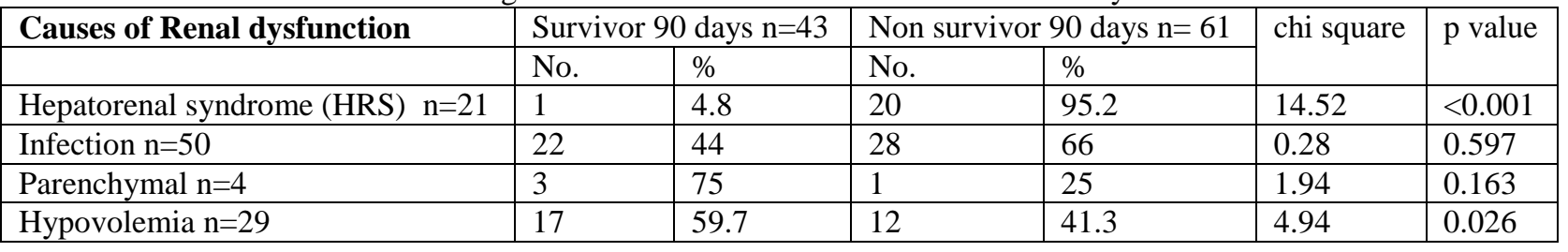

In the present study it was observed HRS group had significantly higher mortality at 90 day $(\mathrm{p}<0.001)$. Hypovolemia group had significantly higher survival $(\mathrm{p}=0.02)$.(Table2) There was a significantly higher AKI stages observed with non survivors at 90 days as compared to survivors at 90 days ( $\mathrm{p}<0.001$ ). In the present study regression in renal dysfunction was seen in $75.5 \%$ in survivor group which was significantly higher as compared to non survivor group at 90 days $\mathrm{p}<0.001$. In our study no response to treatment was seen in $96.3 \%$ non survivors which was significantly higher compared to $3.7 \%$ survivors at 90 days $(\mathrm{p}<0.001)$. (Table 3 )

Table 3:-Risk Stratification according to IAC AKI classification and survival at 90 days

\begin{tabular}{|l|l|l|l|}
\hline Groups & $\begin{array}{l}\text { Survivor } \\
\mathrm{n}=43(\%)\end{array}$ & $\begin{array}{l}\text { Non survivor } \\
\mathrm{n}=61(\%)\end{array}$ & $\mathrm{p}$ value \\
\hline AKI stage I & $31(79.4)$ & $8(20.6)$ & 0.03 \\
\hline AKI stage II & $10(23.2)$ & $33(76.7)$ & 0.73 \\
\hline AKI stage III & $2(9.1)$ & $20(90.9)$ & 0.045 \\
\hline Progression of AKI stage & $1(3.8)$ & $25(96.2)$ & 0.003 \\
\hline Regression of AKI stage & $34(75.5)$ & $11(24.5)$ & 0.0019 \\
\hline Stabilization of AKI stage & $8(24.2)$ & $25(75.8)$ & 0.34 \\
\hline $\begin{array}{l}\text { Complete response to } \\
\text { treatment }\end{array}$ & $33(73.3)$ & $18(38.2)$ & 0.006 \\
\hline $\begin{array}{l}\text { Partial response to } \\
\text { treatment }\end{array}$ & $9(28.1)$ & $23(71.9)$ & 0.34 \\
\hline No response to treatment & $1(3.7)$ & $26(96.3)$ & 0.005 \\
\hline
\end{tabular}

We observed that HRS group was significantly non responsive to treatment in $57.1 \%$ as compared to complete response $0 \%$ and partial response $42.8 \%$ groups ( $\mathrm{p}<0.001$ ). On the other hand hypovolemia patients were significantly complete responsive to treatment $62 \%$ as compared to partial response $24.3 \%$ and no response groups $13.7 \%(\mathrm{p}=0.046)$. In infection and parenchymal renal disease there was no significant difference in complete response, non response and partial response to treatment seen in renal dysfunction. (Table 4)

Table 4:-Treatment response according to etiology of renal dysfunction.

\begin{tabular}{|l|l|l|l|l|l|}
\hline Causes of Renal dysfunction & $\begin{array}{l}\text { No response } \\
\mathrm{n}=27(\%)\end{array}$ & $\begin{array}{l}\text { Complete response } \\
\mathrm{n}=45(\%)\end{array}$ & $\begin{array}{l}\text { Partial response } \\
\mathrm{n}=32(\%)\end{array}$ & chi square & $\mathrm{p}$ value \\
\hline Hepatorenal syndrome (HRS) $\mathrm{n}=21$ & $12(57.1)$ & $0(0)$ & $9(42.8)$ & 22.5 & $<0.001$ \\
\hline Infection $\mathrm{n}=50$ & $11(22)$ & $25(50)$ & $14(28)$ & 1.83 & 0.400 \\
\hline Parenchymal $\mathrm{n}=4$ & $0(0)$ & $2(50)$ & $2(50)$ & 1.62 & 0.444 \\
\hline Hypovolemia $\mathrm{n}=29$ & $4(13.7)$ & $18(62)$ & $7(24.3)$ & 6.15 & 0.046 \\
\hline
\end{tabular}


Figure 1:-Kaplan Meier survival curve as per cause for renal function in cirrhosis.

Survival Functions

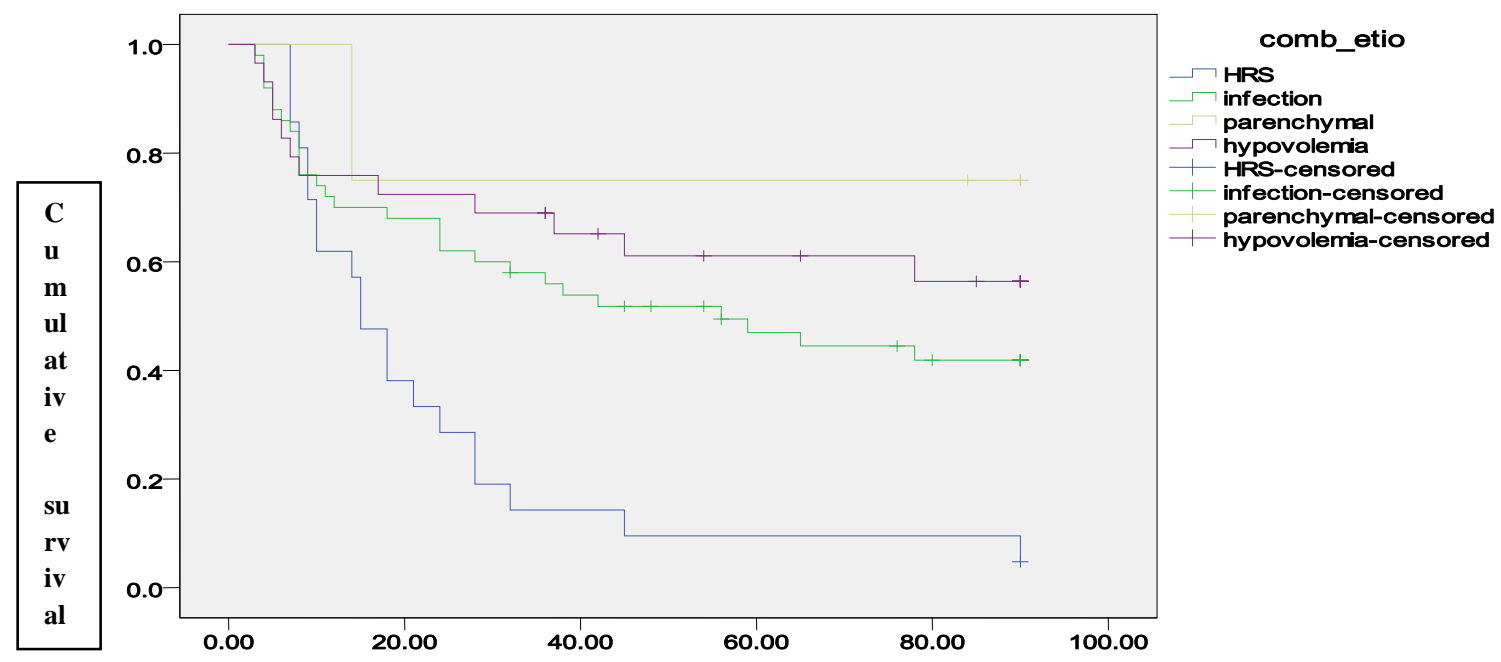

Cumulative survival proportion appears to be much lower with HRS, followed by infection, hypovolemia and parenchymal etiology, on comparison of log rank test it was observed that overall survival distributions between groups was significantly different $\mathrm{p}<0.001$ (Figure1).

Figure 2:-Kaplan Meir Survival Curve for AKI stages at presentation

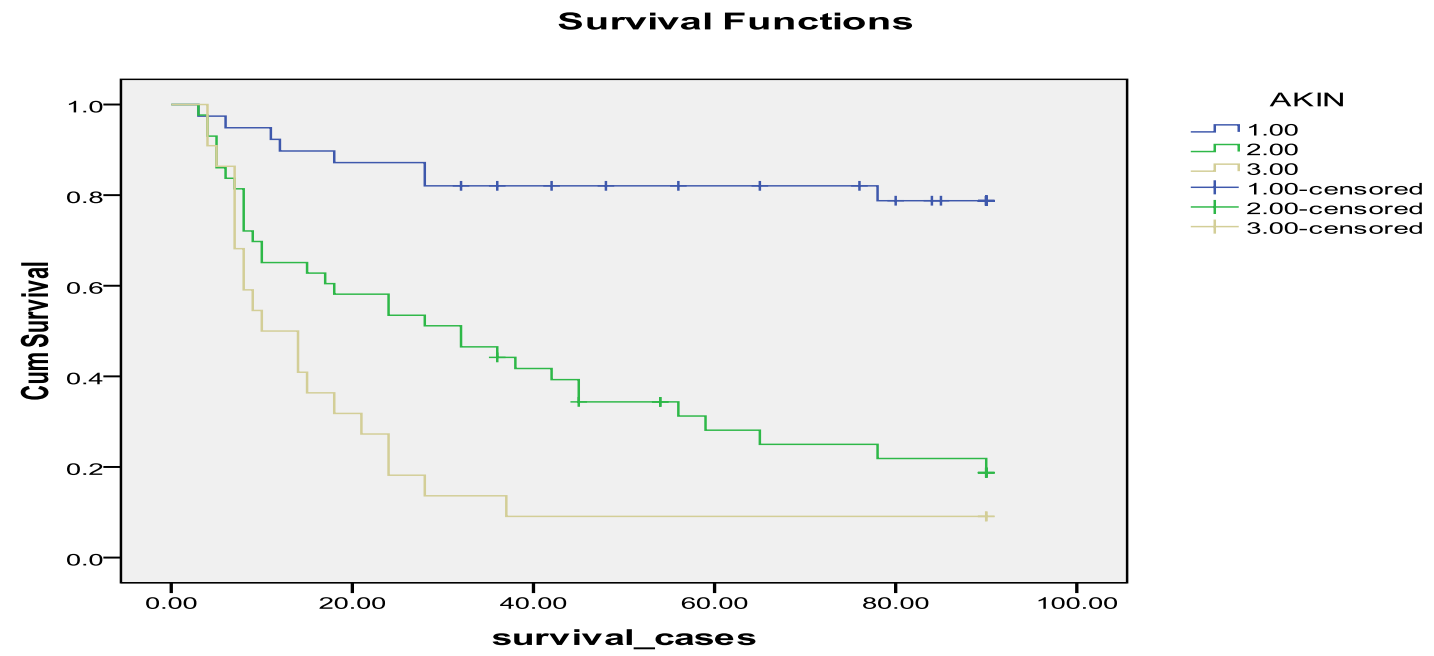

Cumulative survival proportion appears to be much lower with higher AKIN class, on comparison of log rank test it was observed that overall survival distributions between groups was significantly different in AKI class $p<$ 0.0001.(Figure 2)

\section{Discussion:-}

A prevalence of renal dysfunction of $31 \%$ among consecutive cirrhotic patients admitted in our hospital was noted. Acute kidney injury (AKI) has been reported in 20-49\% of hospitalized patients with cirrhosis in various studies .${ }^{(4,5)}$ This prevalence is higher than previously reported ${ }^{(6)}$ which is likely to be related to the use of the expanded definition of AKI recommended by International Club of Ascites [ICA]. ${ }^{(1)}$ Alcohol was significantly major etiological factor causing renal dysfunction in cirrhotic. Angeli et al showed similar results in a study from Spain in 
which alcohol as compared to other causes of cirrhosis, had increased risk for causing renal dysfunction. ${ }^{(7)}$.The reasons are not yet known but if proven it is another area for research. Salerno F et al demonstrated that most the patients of renal dysfunction presented with ascites, jaundice and hepatic encephalopathy. ${ }^{(8)}$ Watt $\mathrm{K}$ et al observed that most of the patients with HRS present with oliguria, high coloured urine, ascites, change in mental status, nausea, vomiting and GI bleed. ${ }^{(9)}$ Similar presentations were seen in our study of renal failure presenting with cirrhotics patients.

\section{Causes of renal dysfunction and outcome:}

Carvalho et al. found renal failure with hypovolemia, infections and HRS in $27 \%, 14 \%$ and $7.6 \%$ of their patients respectively. ${ }^{(2)}$ Martin- Llahi et al. ${ }^{(3)}$ showed infections, hypovolemia, hepatorenal syndrome and parenchymal disease as main etiology of renal dysfunction in patients with liver cirrhosis accounting for $46 \%, 32 \%, 13 \%$ and $9 \%$ respectively. All these studies adopted different criteria for defining causes of renal dysfunction which may be the reason for the difference in results observed.

The pathogenic mechanism of renal failure in patients with cirrhosis and bacterial infections is not completely understood, but it is thought to be related to an impairment of the systemic arterial vasodilatation present in cirrhosis because of bacterial products or increased serum levels of cytokines (tumour necrosis factor $\alpha$, interleukin-6), nitric oxide and other endogenous vasodilators are synthesized in relation with the infection. ${ }^{(115,116)}$ Our results indicate that almost any bacterial infection may cause renal failure in cirrhosis, yet the most frequent was urinary tract infection followed by spontaneous peritonitis, respiratory and skin infections.

In our study infections were most common cause of renal dysfunction $50(49.1 \%)$ out of 104 patients and 90 day mortality being $66 \%$ among 50 patients in this group. Renal dysfunction due to infection respond better to treatment as compared to HRS.

Hypovolemia-related renal failure was the second most common cause of renal failure in our study (28.7\%)and 90 day mortality was $41 \%$ among 29 patients in this group which were statistically significant as compared to other causes of renal dysfunction $\mathrm{p}<0.05$. In survival analysis hypovolemia as compared with infection and hepatorenal syndrome had better survival .Similar results were observed in study by Martin et al and Carvalho et al, ${ }^{(2,3)}$ that renal dysfunction due to hypovolemia had comparatively better survival.

Hepatorenal syndrome (HRS) was the third most common cause of renal failure, accounting for $11 \%$ of cases of renal failure in cirrhosis. Patients with HRS had progressive renal dysfunction and had no response to treatment $(57.1 \%, \mathrm{p}<0.001)$ as compared with other causes of renal failure. 90 day survival associated with HRS was o 1 out of total 21 patients of HRS .Prognosis is invariably poor ranging from weeks to months in type 1 HRS. ${ }^{(12,13)}$ In 2005, Alessandria et al. studied 105 patients with cirrhosis and HRS showed a median survival of one month. ${ }^{(12)}$ This suggests that in cirrhosis, renal failure of hemodynamic origin has a greater negative effect on survival than renal failure of intrinsic renal origin and parenchymal disease.

Parenchymal nephropathy was not found to be a significant cause of renal failure in our study, 4 out of 112 patients had parenchymal diseases with renal dysfunction. The most probable explanation for the good short time prognosis of patients with renal failure due to parenchymal renal diseases is that most of these patients had renal failure in the setting of a remarkably preserved liver and circulatory function.

The main finding of the present study is that the categorization of patients with cirrhosis and renal failure in 4 different groups with the use of a simple classification that is based on the cause of renal failure has prognostic relevance. This classification is based on clinical and analytical data and can be used in all settings. Patients with the best survival are those with renal failure due to parenchymal nephropathy, followed by patients with hypovolemia related renal failure and then patients with infection associated renal failure while patients with HRS had worst survival.

\section{AKI stages and outcome}

In our study, AKI stages, higher mortality was seen in stage III at 90 days was $90 \%$. Survival at 90 days was best in patients in stage I AKI (79.4\%) .Survival at 90 days was highest with patients complete response to treatment (73.3\%).In a study conducted by Carvalho et al. ${ }^{(14)}$, AKI incidence within the first $48 \mathrm{~h}$ of hospitalization was $46 \%$ in cirrhotic patients with ascites, using AKIN criteria. The mortality rates for patients with and without AKI were 
$52.7 \%$ and $29.9 \%$, respectively, and AKI was found to be independently associated with mortality. In a study conducted by Belcher et al. ${ }^{(15),}$ who used AKIN criteria and analysed 192 patients with AKI, total mortality rate was $26 \%$. They found mortality rates of $22 \%, 23 \%$ and $39.5 \%$ for stage 1 , stage 2 and stage $3 \mathrm{AKI}$, respectively.

One of the important findings in our study was the significant relation between AKI progression and mortality. In a study conducted by Belcher et al. ${ }^{(15)}$, similar to our results, a fourfold increase in mortality in patients with AKI progression was reported. The same study showed that there was a decrease in mortality rate for patients with an early recovery of AKI.

\section{Conclusions:-}

Prevalence of renal dysfunction among cirrhotics was high. Survival was worst in patients with hepatorenal syndrome. Survival Mortality was more in patients who did not respond to treatment and who had progressive renal dysfunction.We suggest that the inclusion of etiology of renal dysfunction and stage of AKI at admission may further improve the accuracy in predicting the outcome.

\section{Bibliography:-}

1. Angeli P, Gines P, Wong F, Bernardi M, Boyer TD, Gerbes A, et al. Diagnosis and management of acute kidney injury in patients with cirrhosis: revised consensus recommendations of the International Club of Ascites. Journal of Hepatology. 2015 Apr;62(4):968-74.

2. Carvalho GC, Regis Cde A, Kalil JR, et al. Causes of renal failure in patients with decompensated cirrhosis and its impact in hospital mortality. Annals of Hepatology 2012;11(1):90-95.

3. Martin-Llahi M, Guevara M, Torre A, et al. Prognostic importance of the cause of renal failure in patients with cirrhosis. Gastroenterology 2011;140(2):488-496.

4. 4.Garcia-Tsao G, Parikh CR, Viola A. Acute kidney injury in cirrhosis. Hepatology. 2008; 48(6):2064-2077.

5. Wong F, O'Leary JG, Reddy KR, Patton H, Kamath PS, Fallon MB, et al. New consensus definition for acute kidney injury accurately predicts 30-day mortality in cirrhosis with infection. Gastroenterology 2013;145:12801288.84.

6. Follo A, Llovet JM, Navasa M, et al. Renal impairment after spontaneous bacterial peritonitis in cirrhosis: incidence, clinical course, predictive factors and prognosis. Hepatology 1994;20:1495-1501.

7. Angeli P,Rodríguez E, Piano S, et al. Acute kidney injury and acute-on-chronic liver failure classifications in prognosis assessment of patients with acute decompensation of cirrhosis.Gut 2015;64:1616-1622.

8. Salerno F, Borroni G, Moser P, Badalamenti S, Cassara L, Maggi A, etal. Survival and prognostic factors of cirrhotic patients with ascites: a study of 134 out patients. American Journal Gastroenterology 1993;88:514-19.

9. Watt K, Uhanova J, Minuk GY. Hepatorenal syndrome: diagnostic accuracy, clinical features and outcome in a tertiary care center. American Journal Gastroenterology 2002;97(8):1868-70.

10. Ginès P, Cardenas A, Arroyo V, et al. Management of cirrhosis and ascites. New England Journal of Medicine 2004;350:1646-1654.

11. Sort P, Navasa M, Arroyo V, et al. Effect of intravenous albumin on renal impairment and mortality in patients with cirrhosis and spontaneous bacterial peritonitis. New England Journal of Medicine 1999;341:403-409.

12. Fang JT, Tsai MH, Tian YC, Jenq CC, Lin CY, Chen YC, et al. Outcome predictors and new score of critically ill cirrhotic patients with acute renal failure. Nephrology Dialysis Transplant.2008; 23(6):1961-1969.

13. M. Schepke, B. Appenrodt, J. Heller, J. Zielinski, and T. Sauerbruch, Prognostic factors for patients with cirrhosis and kidney dysfunction in the era of MELD: results of a prospective study. Liver International, 2006;26: 834-839.

14. Carvalho JR, Villela-Nogueira CA, Luiz RR, et al. Acute kidney injury network criteria as a predictor of hospital mortality in cirrhotic patients with ascites. Journal Clinical Gastroenterology $2011 ; 46(3):$ e21-6.

15. Belcher JM, Garcia-Tsao G, Sanyal AJ, et al. Association of AKI with mortality and complications in hospitalized patients with cirrhosis. Hepatology 2013;57(2):753-762. 